\title{
Consolidated Bioprocessing for Butyric Acid Production from Rice Straw with Undefined Mixed Culture
}

\section{OPEN ACCESS}

Edited by:

Vijai Kumar Gupta,

National University of Ireland, Galway,

Ireland

Reviewed by:

Toru Matsui,

University of the Ryukyus, Japan

Naresh Singhal,

University of Auckland, New Zealand

*Correspondence: Jianzheng $L$

jianzhengli@hit.edu.cn

Specialty section:

This article was submitted to Microbiotechnology, Ecotoxicology

and Bioremediation,

a section of the journal

Frontiers in Microbiology

Received: 02 July 2016 Accepted: 04 October 2016 Published: 24 October 2016

Citation:

Ai B, Chi X, Meng J, Sheng Z, Zheng L, Zheng $X$ and Li J (2016)

Consolidated Bioprocessing for Butyric Acid Production from Rice Straw with Undefined Mixed Culture.

Front. Microbiol. 7:1648.

doi: 10.3389/fmicb.2016.01648

\author{
Binling $\mathrm{Ai}^{1,2}$, Xue Chi ${ }^{2}$, Jia Meng ${ }^{2}$, Zhanwu Sheng ${ }^{1}$, Lili Zheng ${ }^{1}$, Xiaoyan Zheng ${ }^{1}$ and \\ Jianzheng $L i^{2 *}$ \\ ${ }^{1}$ Haikou Experimental Station, Chinese Academy of Tropical Agricultural Sciences, Haikou, China, ${ }^{2}$ State Key Laboratory of \\ Urban Water Resource and Environment, Harbin Institute of Technology, Harbin, China
}

Lignocellulosic biomass is a renewable source with great potential for biofuels and bioproducts. However, the cost of cellulolytic enzymes limits the utilization of the low-cost bioresource. This study aimed to develop a consolidated bioprocessing without the need of supplementary cellulase for butyric acid production from lignocellulosic biomass. A stirred-tank reactor with a working volume of $21 \mathrm{~L}$ was constructed and operated in batch and semi-continuous fermentation modes with a cellulolytic butyrate-producing microbial community. The semi-continuous fermentation with intermittent discharging of the culture broth and replenishment with fresh medium achieved the highest butyric acid productivity of $2.69 \mathrm{~g} /(\mathrm{L} \cdot \mathrm{d})$. In semi-continuous operation mode, the butyric acid and total carboxylic acid concentrations of 16.2 and $28.9 \mathrm{~g} / \mathrm{L}$, respectively, were achieved. Over the 21-day fermentation period, their cumulative yields reached 1189 and 2048 $\mathrm{g}$, respectively, corresponding to 41 and $74 \%$ of the maximum theoretical yields based on the amount of $\mathrm{NaOH}$ pretreated rice straw fed in. This study demonstrated that an undefined mixed culture-based consolidated bioprocessing for butyric acid production can completely eliminate the cost of supplementary cellulolytic enzymes.

Keywords: butyric acid production, rice straw, consolidated bioprocessing, undefined mixed culture, carboxylate platform

\section{INTRODUCTION}

Butyric acid is a widely applied material in the chemical, textile, food and pharmaceutical industries (Zhang et al., 2009) with potential application in the production of biofuel butanol (Richter et al., 2012; Lee et al., 2014) and biodegradable plastics (Albuquerque et al., 2011). The industrial-scale production of butyric acid is currently accomplished by petrochemical processes (Dwidar et al., 2012). Butyric acid fermentation from renewable biomass may provide a reasonable alternative. However, because of the increasing price of fermentation feedstocks, namely corn and molasses, traditional butyric acid fermentation is not economically attractive. Using lignocellulosic biomass as the fermentation feedstock provides environmental and cost benefits, although the benefits gained from the low feedstock cost is completely counteracted by the cost of cellulolytic enzymes. In a sugar platform, the best-known biorefinery platform, cellulolytic enzymes are required to break down lignocelluloses into five- and six-carbon sugars that are further converted to desired chemicals, for example, ethanol (Agler et al., 2011). By contrast, purified cellulolytic enzymes are not necessary for lignocellulose conversion through a carboxylate platform, another biorefinery platform. Using a carboxylate platform, organic feedstocks are anaerobically converted 
by undefined mixed cultures into short-chain carboxylates (including acetate, propionate, lactate, and butyrate) as intermediate feedstock chemicals (Agler et al., 2011). By employing an undefined mixed culture as the source of fermentation organisms, the cost of added enzymes is completely eliminated, and it becomes possible to convert cellulosic feedstocks into the desired products in a single process termed consolidated bioprocessing (CBP). In CBP, cellulolytic enzyme production, both cellulose and hemicellulose hydrolysis, and fermentation to obtain desired products are combined in a single process step (Olson et al., 2012). CBP is the ultimate low-cost configuration for cellulose hydrolysis and fermentation because the highly integrated process requires less feedstock processing, lower energy inputs and yields a higher conversion efficiency (Fu and Holtzapple, 2010). The carboxylate platform-based MixAlco process, an example of CBP, employs a mixed culture of acid-forming microorganisms to convert lignocellulosic biomass to carboxylates which are subsequently chemically converted to other chemical and fuel products (Granda et al., 2009; Holtzapple and Granda, 2009). In the MixAlco process, sugarcane bagasse (Fu and Holtzapple, 2011), corn stover (Chan et al., 2011), office paper and pineapple residue (Forrest et al., 2010) with chicken manure as a co-substrate have been used for carboxylate production, primarily acetate. After inoculation with a mixed culture of marine microorganisms, a yield of $14.6-56.1 \mathrm{~g} / \mathrm{L}$ of total carboxylic acids, of which 65.9 to $90.6 \%$ was acetic acid, was produced from a mixed feed of $80 \%$ lime-treated sugarcane bagasse with $20 \%$ chicken manure (Fu and Holtzapple, 2010).

Inspired by the carboxylate platform and $\mathrm{CBP}$, undefined mixed culture-based fermentation technology is a promising alternative strategy for butyric acid production from lignocellulosic biomass. In a previous study, an anaerobic microbial community with stable cellulose-degrading potential and high selectivity for butyric acid production was selected from a combination of cattle manure, pig manure compost, corn field soil and rotten wood (Ai et al., 2013). To further demonstrate the feasibility and potential of undefined mixed culture for butyric acid production, a $\mathrm{CBP}$ process was investigated to produce butyric acid from $\mathrm{NaOH}$ pretreated rice straw using a cellulosedegrading butyric acid-producing microbial community, and its fermentation performance in batch and semi-continuous operations was evaluated.

\section{MATERIALS AND METHODS}

\section{Experimental Set-Up}

A stirred-tank reactor with a working volume of $21 \mathrm{~L}$ was constructed for butyric acid fermentation (Figure 1). The fermentation temperature was maintained at $35 \pm$ $1^{\circ} \mathrm{C}$ by wrapping heating wire around the reactor. A wet gas meter was used for the measurement of biogas volume. The water seal and wet gas meter were filled with acidified water $(\mathrm{pH} 3)$ to prevent the dissolution of $\mathrm{CO}_{2}$ contained in the biogas. The fermentation $\mathrm{pH}$ was controlled from 6.0 to 6.2 with saturated $\mathrm{NaHCO}_{3}$ solution as the buffer.

\section{Sodium Hydroxide Pretreatment of Rice Straw}

Sodium hydroxide pretreatment is performed for efficient utilization of rice straw, the substrate for butyric acid fermentation. $\mathrm{NaOH}$ pretreatment is recognized as an effective method for delignification as well as swelling of biomass to increase digestibility. The was cut into $10-$ to $15-\mathrm{cm}$ lengths and soaked in a $1 \% \mathrm{NaOH}$ solution with a solid-to-liquid ratio of $1: 15(\mathrm{w} / \mathrm{v})$ at $50^{\circ} \mathrm{C}$ for $72 \mathrm{~h}$ in static state. The solid residue was then separated by filtering and thoroughly washed with tap water to near-neutral $\mathrm{pH}$. The neutralized residue was squeezed and stored at $4{ }^{\circ} \mathrm{C}$. The substrate contained 53.0\% cellulose, $27.4 \%$ hemicellulose and $8.0 \%$ lignin. The untreated rice straw contained $39.7 \%$ cellulose, $24.8 \%$ hemicellulose and $15.3 \%$ lignin. The cellulose, hemicellulose and lignin were measured as previously described (Van Soest et al., 1991).

\section{Preparation of Inoculum}

The cellulolytic butyrate-producing mixed culture was derived from cattle manure, pig manure compost, corn field soil and rotten wood (Ai et al., 2013). The cattle manure, pig manure compost and corn field soil were collected from the suburb of Harbin, China. The rotten wood was collected from the campus of Northeast Forestry University, Harbin, China. All samples were taken in May, 2012 at locations 10 to $20 \mathrm{~cm}$ below the surface. The mixed culture was selected as a producer of butyric acid for its stable cellulose-degrading potential and high selectivity of butyric acid production from $\mathrm{NaOH}$ pretreated rice straw. The mixed culture includes cellulolytic and xylanolytic bacteria, butyrate-producing bacteria and other acidogenic bacteria. For the inoculum preparation, the stored mixed culture was transferred to seed medium which was composed of $10 \mathrm{~g}$ pretreated rice straw, $5 \mathrm{~g}$ tryptone, $1 \mathrm{~g}$ yeast extract, $5 \mathrm{~g} \mathrm{NaCl}, 2 \mathrm{~g} \mathrm{CaCO}_{3}$, and $0.5 \mathrm{~g}$ D-cysteine hydrochloride per liter, and one filter paper strip $(1.5 \times 5 \mathrm{~cm})$ as an indicator. The broth was purged with nitrogen gas for $10 \mathrm{~min}$ to maintain anaerobic conditions, after which the $500-\mathrm{mL}$ serum bottle containing $300 \mathrm{~mL}$ of broth was sealed and autoclaved at $115^{\circ} \mathrm{C}$ for $20 \mathrm{~min}$. Following inoculation with $10 \mathrm{~mL}$ of the stored culture, the bottle was incubated at $35^{\circ} \mathrm{C}$ without agitation until the filter paper strip was broken down.

\section{Butyric Acid Fermentation Procedure}

The butyric acid fermentation medium was composed of 90 g pretreated rice straw, $5 \mathrm{~g}$ tryptone, $1 \mathrm{~g}$ yeast extract, 5 $\mathrm{g} \mathrm{NaCl}, 6 \mathrm{~g} \mathrm{CaCO}_{3}, 0.5 \mathrm{~g}$ D-cysteine hydrochloride and $0.08 \mathrm{~g}$ chloroform per liter. Chloroform was used as an inhibitor of methanogenic bacteria. The fermentation reactor and medium were prepared without $\mathrm{N}_{2}$ purging and autoclaving. Fermentations were initiated by inoculating $1 \mathrm{~L}$ inoculum into $20 \mathrm{~L}$ of fermentation medium. In batch operation, aside from the $\mathrm{NaHCO}_{3}$ buffer, no additional medium ingredients were added to the fermentation system after the initial charge. For the semicontinuous operation, on the fourth day and every day thereafter throughout the fermentation period, $3 \mathrm{~L}$ fermentation broth was 


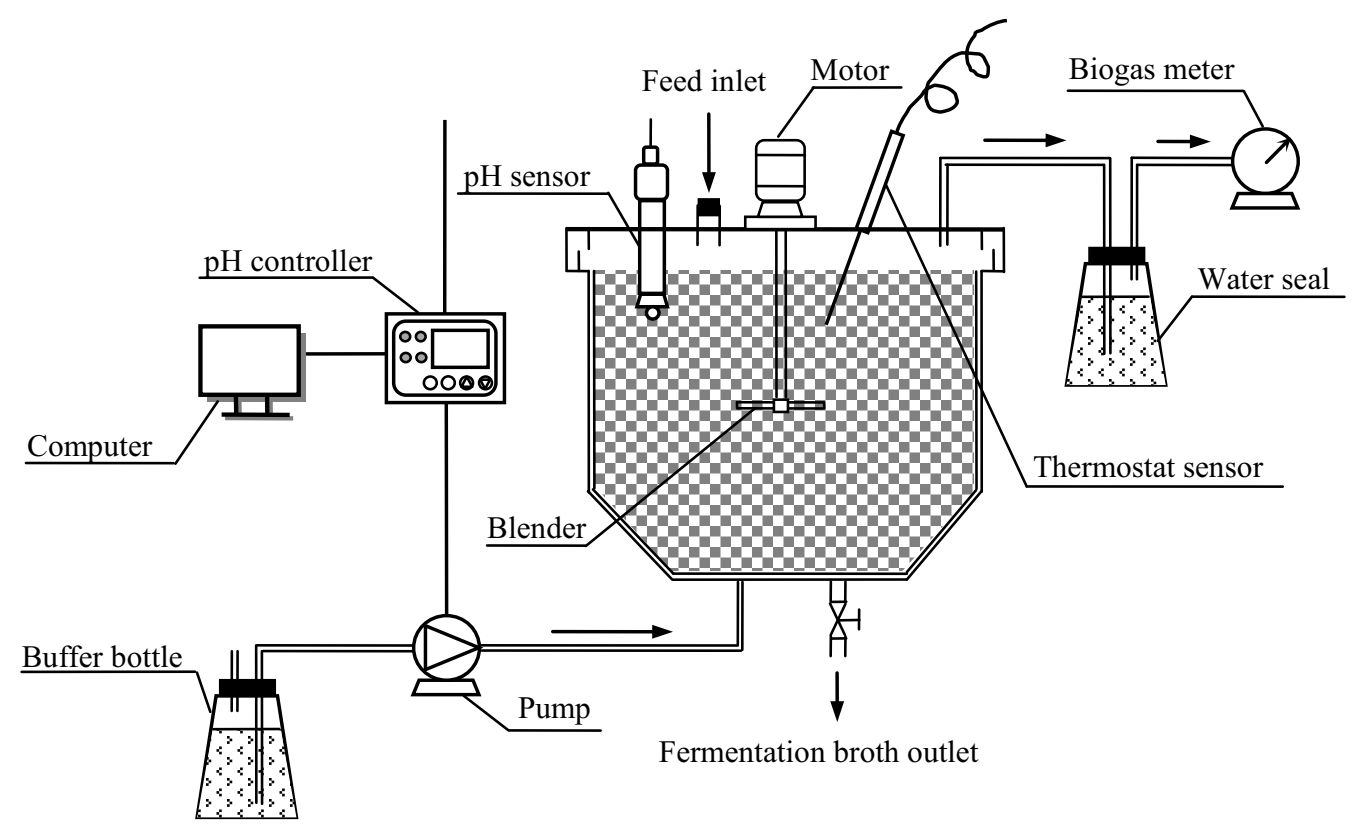

FIGURE 1 | Schematic diagram of the stirred-tank reactor system for butyric acid fermentation.

discharged and then $3 \mathrm{~L}$ fresh fermentation medium containing only $270 \mathrm{~g}$ pretreated rice straw and $15 \mathrm{~g}$ tryptone was added to the system.

\section{Analytical Methods}

The daily biogas production volume was monitored using a wet gas meter (LML-1, Changchun Automotive Filter Co., LTD., Changchun, China). Hydrogen, methane and carbon dioxide in the biogas were analyzed using a gas chromatography (SP6800A, Lunan Instrument Factory, Shandong, China) equipped with a thermal conductivity detector and a $2 \mathrm{~m}$ stainless column packed with Porapak Q (60/80 mesh, ZhongKeKaiDi Chemical New-tech Co., Ltd., Lanzhou, China). Carboxylic acids in the fermentation broth were measured using a gas chromatography (SP-6800A, Lunan Instrument Factory) equipped with a flame ionization detector and a FFAP capillary column $(30 \mathrm{~m} \times$ $0.32 \mathrm{~mm} \times 0.50 \mu \mathrm{m}$, ZhongKeKaiDi Chemical New-tech Co., Ltd.). Microbial biomass was estimated by optical density at $260 \mathrm{~nm}$ of fermentation broth after $\mathrm{HClO}_{4}$ hydrolysis as follows: To $5 \mathrm{~mL}$ of the culture broth, $5 \mathrm{~mL}$ of $1 \mathrm{~mol} / \mathrm{L} \mathrm{HClO}_{4}$ solution was added. If required, the samples were diluted to adjust the optical density within the readable range. The tubes were placed in boiling water for $20 \mathrm{~min}$ and cooled to room temperature. The contents of the tubes were centrifuged and the OD of the supernatant was measured at $260 \mathrm{~nm}$. The $\mathrm{OD}_{260}$ of cultured broth was denoted by [A]. Uncultured broth was used as a blank, and the $\mathrm{OD}_{260}$ was denoted by [B]. The microbial biomass was denoted as $[\mathrm{A}]-[\mathrm{B}]$. The detailed operating conditions for determination of biogas composition, carboxylic acids and microbial biomass were as described previously (Ai et al., 2014b).

\section{Statistical Analysis}

Statistical analysis was performed using Statistical Product and Service Solutions (IBM SPSS Statistics for Windows, Version 19.0, IBM Corp., New York, US).

\section{RESULTS AND DISCUSSION \\ Butyric Acid Production by Batch Fermentation}

Two batches of butyric acid fermentation in batch operation were conducted with run times of 10 and 12 days. Figure 2 shows the time courses of the batch fermentation of butyric acid from rice straw. The two batches of butyric acid fermentation followed a similar pattern, which verified the reproducibility of the mixed culture-based fermentation for butyric acid. Acetic and butyric acids were the main products in the fermentation broth from the eight kinds of carboxylic acids detected. The acids found at low concentrations are not shown in the figure. The fermentations underwent a 1-day lag phase followed by the rapid degradation of rice straw over the following 3 days. Similar to the degradation of rice straw, the carboxylic acids and hydrogen production increased from the second day and leveled off from the sixth day onwards. The acetic acid concentration peaked on the third day and then began to decrease the next day. The changes in butyric acid concentration lagged a day behind those observed for acetic acid, increasing rapidly on the third and fourth days. From the plot of product selectivity (percent of butyric acid from the total carboxylic acids) vs. time, it was evident that acetic acid was the primary carboxylic acid produced in the first 2 days with a product selectivity of about $25 \%$. Over the following several days, the product selectivity increased to and was maintained at around 


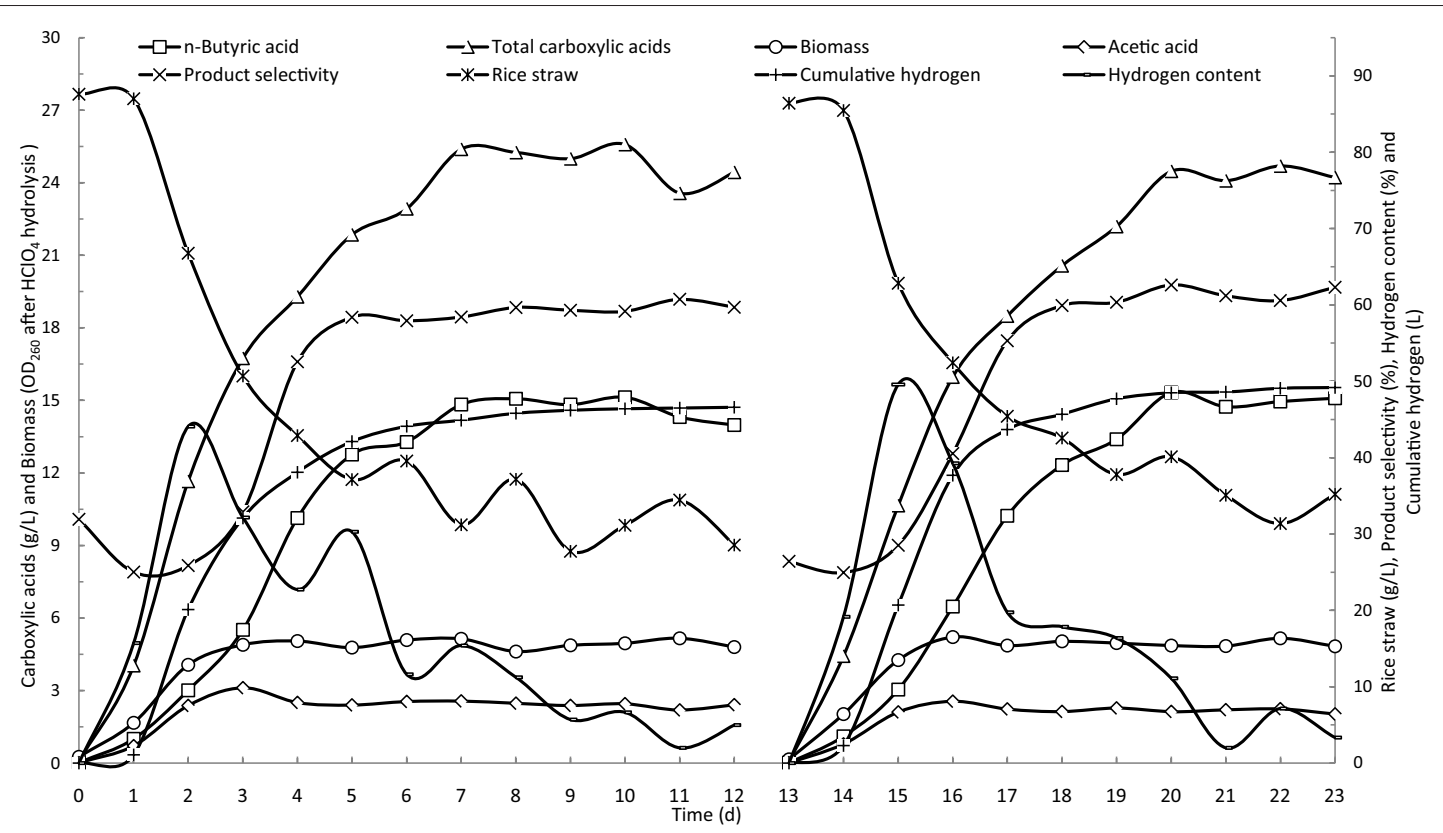

FIGURE 2 | Time courses of butyric acid production by batch fermentation in a stirred-tank reactor.

$60 \%$, indicating that butyric acid was the major product of the fermentation.

The cell biomass represented by the $\mathrm{OD}_{260}$ of the fermentation broth after $\mathrm{HClO}_{4}$ hydrolysis reached its maximum weight in the first 3 days, with little change over the remaining fermentation period. During the primary stage of fermentation, a large amount of hydrogen was generated in the reactor. The peak production of $20 \mathrm{~L} / \mathrm{d}$ was observed on the second day and then quickly decreased. Hydrogen is a clear and sustainable energy source (Cheng et al., 2011). Additionally, as a reducing agent, hydrogen can be used to reduce carboxylic acids to alcohol fuels via chemical post-processing reactions, including ketonization and hydrogenation (Agler et al., 2011).

\section{Butyric Acid Production by Semi-Continuous Fermentation}

In batch operation, the consumption of rice straw and production of butyric acid reached their maximum rates on the fourth day of fermentation, and essentially decreased to zero after 7 days (Figure 2). Based on the results of batch fermentation, semi-continuous fermentation was implemented by discharging $3 \mathrm{~L}$ of fermentation broth and then feeding with $3 \mathrm{~L}$ of fresh fermentation medium from the fourth day and every day thereafter throughout the fermentation period. The detailed fermentation course of butyric acid production using the semi-continuous operation is presented in Figure 3. On the fourth day, the consumption of rice straw began to decrease. Upon the addition of fresh fermentation medium, the substrate consumption rate on the fifth day rebounded to $14.0 \mathrm{~g} /(\mathrm{L} \cdot \mathrm{d})$ from $7.4 \mathrm{~g} /(\mathrm{L} \cdot \mathrm{d})$ on the fourth day. However, from the tenth day onwards, the rice straw remaining in the fermentation broth continued to increase, indicating that substrate consumption decreased, likely as a result of strain degeneration and productivity decline. The total carboxylic acid production slowed down on the fourth day, but sharply increased on the fifth day when fresh substrates were fed to the fermentation system, whereafter, it remained stable with slight fluctuations. The butyric and acetic acid production followed similar changes in productivity over time. However, overall a decreasing trend was observed from the product selectivity curve. Over the last several days, the percent of butyric acid from the total carboxylic acids dropped below $60 \%$. The aforementioned pattern of acetic acid formation, increasing on the second and third days and then decreasing to the basal level, was more clearly observed in the time course of cumulative acetic acid production presented in Figure 4. As shown from the curves of cumulative hydrogen production and hydrogen content, hydrogen generation was generally stable.

\section{Performance of Batch and Semi-Continuous Fermentation for Butyric Acid Production}

Table 1 summarizes the results of batch and semi-continuous fermentation for butyric acid. In the two batches of batch fermentation, 513.2 and $508.6 \mathrm{~g}$ of total carboxylic acids were produced, including 160.4 and $134.8 \mathrm{~g}$ of butyric acid. Because of the longer residence time of the substrate, the degradation rate of rice straw in the batch fermentation (63.4 and 58.9\%) was higher than that in the semi-continuous fermentation (53.4\%). The selectivity of butyric acid production and butyric acid yield in the batch fermentation were higher than those in the semi-continuous fermentation. The microbial cell biomass and 


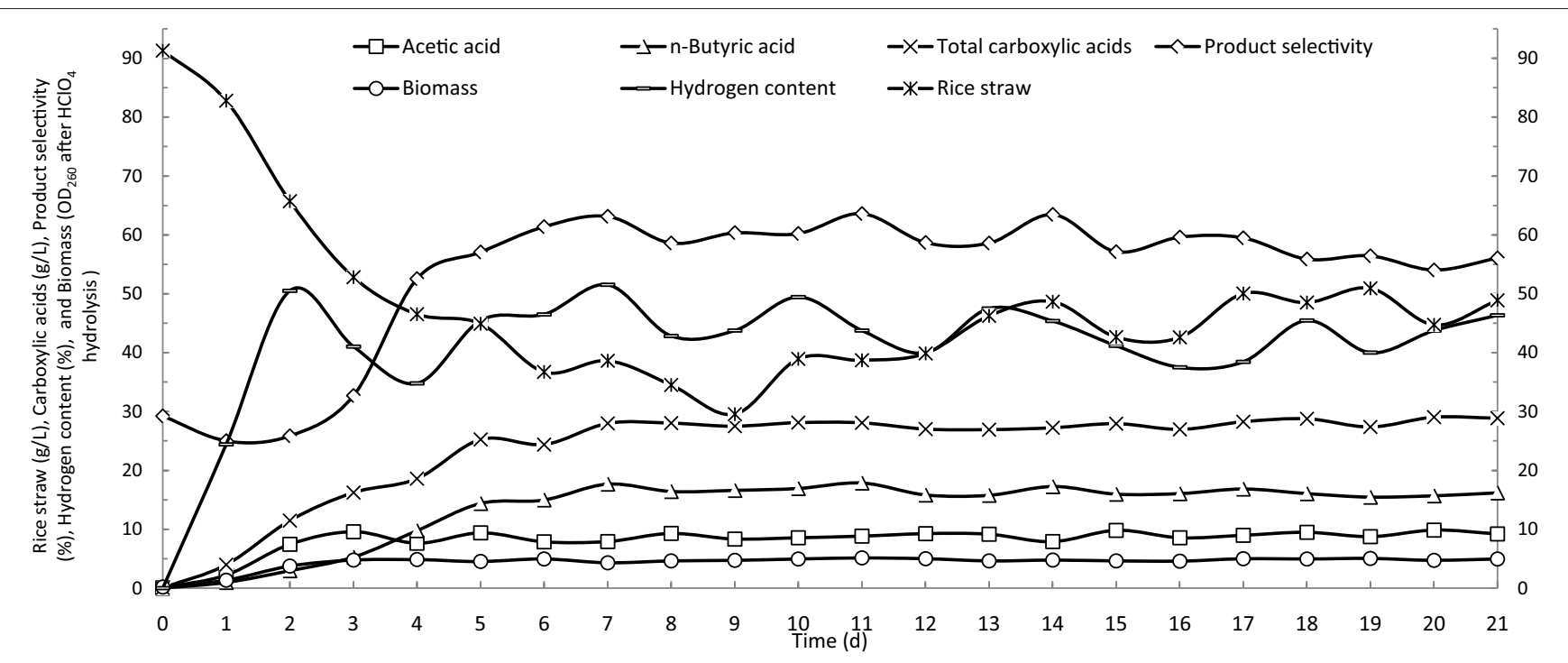

FIGURE 3 | Time courses of butyric acid production by semi-continuous fermentation in a stirred-tank reactor.

carboxylic acid yield were not significantly different in the two fermentation operations. On the contrary, by employing a semi-continuous operation, the reactor volumetric productivity was significantly improved. For example, the butyric acid productivity was increased from 1.68 to $1.90 \mathrm{~g} /(\mathrm{L} \cdot \mathrm{d})$ in batch fermentation to $2.69 \mathrm{~g} /(\mathrm{L} \cdot \mathrm{d})$ in semi-continuous fermentation, and the carboxylic acid productivity from 2.83 to $3.08 \mathrm{~g} /(\mathrm{L} \cdot \mathrm{d})$ to $4.64 \mathrm{~g} /(\mathrm{L} \cdot \mathrm{d})$ (Table 1$)$. The structure of rice straw and its solid state in the fermentation broth determine the efficiency of the biodigestion, and hence, inefficient biodigestion would yield a low utilization rate. As the fermentation progressed, the increasing lignin content made cellulose and hemicellulose more difficult to utilize, and the increasing carboxylic acids concentration aggravated product inhibition. Additionally, as a consequence of constantly feeding the $\mathrm{NaHCO}_{3}$ solution to buffer the $\mathrm{pH}$, the sodium ion concentration in the fermentation broth continued to increase, which also inhibited the substrate utilization and carboxylic acid production. High $\mathrm{Na}^{+}$concentration affects adenosine triphosphate content and activities of microbial enzymes, such as dehydrogenase and alkaline phosphatase (Hao et al., 2006). In the semicontinuous fermentation, by partly discharging the fermentation broth and then recharging with fresh fermentation medium, inhibition from end-products and $\mathrm{Na}^{+}$can be minimized and the aging of carboxylic acid-fermenting strains can be extended. Furthermore, the semi-continuous fermentation operation shortened the nonproductive time and enhanced both efficiency and productivity. In this study, semi-continuous operation was observed to be more suitable for butyric acid production with an undefined mixed culture.

\section{Theoretical Potential of Rice Straw for Butyric Acid Production}

Cellulose is hydrolyzed to glucose, an intermediate in anaerobic digestion, and hemicellulose to xylose with small amounts of arabinose, mannose, and galactose. For the convenience of calculation, hemicellulose is modeled as xylan in this study. Equations $(1,2)$ show the conversion reactions of cellulose and hemicellulose polymers to monomers.

$$
\begin{aligned}
\left(\mathrm{C}_{6} \mathrm{H}_{10} \mathrm{O}_{5}\right)_{\mathrm{n}}+\mathrm{n} \mathrm{H} \mathrm{H}_{2} \mathrm{O} & \rightarrow \mathrm{n} \mathrm{C}_{6} \mathrm{H}_{12} \mathrm{O}_{6} \\
\left(\mathrm{C}_{5} \mathrm{H}_{8} \mathrm{O}_{4}\right)_{\mathrm{n}}+\mathrm{n} \mathrm{H}_{2} \mathrm{O} & \rightarrow \mathrm{n} \mathrm{C}_{5} \mathrm{H}_{10} \mathrm{O}_{5}
\end{aligned}
$$

In anaerobic environments, during the primary fermentation with an undefined mixed culture, the five- and six-carbon sugars are converted to acetic acid and ethanol (C2), propionic acid and lactic acid (C3) and butyric acid (C4), which can be converted further by secondary fermentation to medium-chain carboxylic acids, for example, caproic acid (C6) and caprylic acid (C8) (Agler et al., 2011). Glucose is metabolized to pyruvate via the Embden-Meyerhof-Parnas (EMP) pathway (Agler et al., 2011), and xylose via the pentose phosphate pathway (PPP) (Temudo et al., 2009). The simplified Equations $(3,4)$ present the metabolic reactions of glucose to acetic acid and butyric acid, respectively.

$$
\begin{gathered}
\text { Glucose } \rightarrow 2 \text { Pyruvate } \rightarrow 2 \text { Acetate }+4 \mathrm{H}_{2}+2 \mathrm{CO}_{2}+4 \operatorname{ATP}(3) \\
\text { Glucose } \rightarrow 2 \text { Pyruvate } \rightarrow \text { Butyrate }+2 \mathrm{H}_{2}+2 \mathrm{CO}_{2}+3 \operatorname{ATP}(4)
\end{gathered}
$$

The simplified Equations $(5,6)$ present the metabolic reactions of xylose to acetic acid and butyric acid, respectively.

$$
\begin{aligned}
3 \text { Xylose } \rightarrow 5 \text { Pyruvate } \rightarrow & 5 \text { Acetate }+10 \mathrm{H}_{2} \\
& +5 \mathrm{CO}_{2}+10 \mathrm{ATP} \\
3 \text { Xylose } \rightarrow 5 \text { Pyruvate } \rightarrow & 2.5 \text { Butyrate }+5 \mathrm{H}_{2} \\
& +5 \mathrm{CO}_{2}+7.5 \mathrm{ATP}
\end{aligned}
$$

Based directly on Equations (1, 3), $0.74 \mathrm{~g}$ of acetic acid can be obtained from $1 \mathrm{~g}$ of cellulose; based on Equations $(2,5), 0.76 \mathrm{~g}$ 


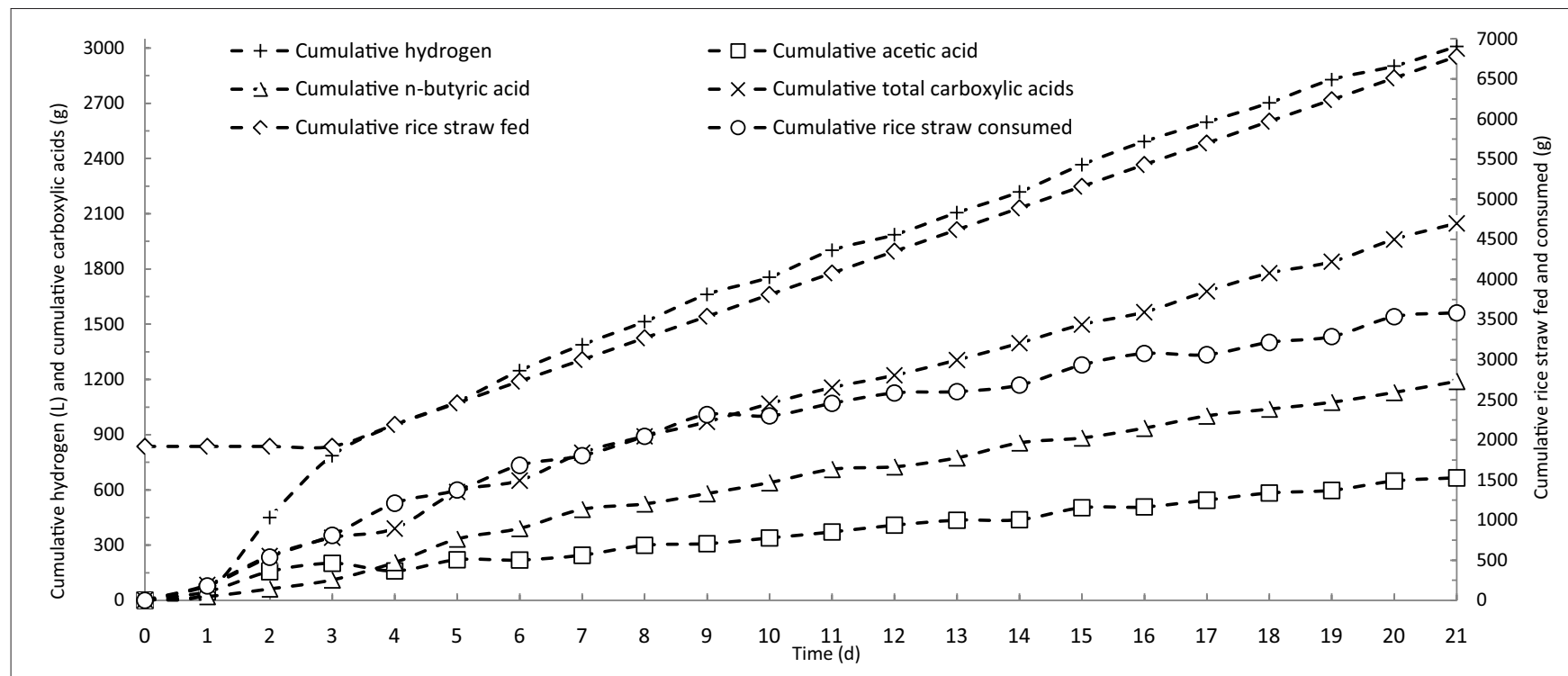

FIGURE 4 | Time courses of cumulative carboxylic acids and hydrogen by semi-continuous fermentation in a stirred-tank reactor.

TABLE 1 | Summary of butyric acid production by batch and semi-continuous fermentation in a stirred-tank reactor.

\begin{tabular}{|c|c|c|c|}
\hline & Batch fermentation 1 & Batch fermentation 2 & Semi-continuous fermentation \\
\hline Fermentation period (d) & 12 & 10 & 21 \\
\hline Solids residence time $(\mathrm{d})^{\mathrm{a}}$ & 12 & 10 & 7 \\
\hline Cumulative acetic acid (g) & 160.4 & 134.8 & 665.3 \\
\hline Cumulative propionic acid (g) & 19.9 & 17.5 & 64.5 \\
\hline Cumulative $i$-butyric acid (g) & 6.7 & 11.3 & 44.6 \\
\hline Cumulative $n$-butyric acid (g) & 293.6 & 316.9 & 1189.4 \\
\hline Cumulative $i$-valeric acid (g) & 13.2 & 12.7 & 39.9 \\
\hline Cumulative $n$-valeric acid (g) & 6.5 & 4.3 & 14.7 \\
\hline Cumulative $i$-caproic acid (g) & 11.0 & 9.7 & 26.8 \\
\hline Cumulative $n$-caproic acid (g) & 1.8 & 1.3 & 2.5 \\
\hline Cumulative total carboxylic acids (g) & 513.2 & 508.6 & 2047.7 \\
\hline Degradation rate of rice straw (\%) & $63.4 \pm 5.4 A^{\mathrm{C}}$ & $58.9 \pm 5.1 A$ & $53.4 \pm 0.9 B$ \\
\hline Product selectivity (\%) ${ }^{b}$ & $59.4 \pm 0.3 A$ & $60.9 \pm 0.3 B$ & $58.1 \pm 0.4 C$ \\
\hline Biomass $\left(\mathrm{OD}_{260}\right.$ after $\mathrm{HClO}_{4}$ hydrolysis) & $5.01 \pm 0.05 A$ & $4.94 \pm 0.2 A$ & $4.92 \pm 0.17 A$ \\
\hline Butyric acid yield (g/g rice straw fed) & $0.171 \pm 0.002 A B$ & $0.174 \pm 0.003 A$ & $0.167 \pm 0.001 B$ \\
\hline Carboxylic acids yield (g/g rice straw fed) & $0.29 \pm 0.00 A$ & $0.28 \pm 0.00 A$ & $0.29 \pm 0.00 A$ \\
\hline Cumulative $\mathrm{H}_{2}$ yield (mL/g rice straw fed) & $26.33 \pm 0.17 A$ & $27.8 \pm 0.2 B$ & $21.6 \pm 0.3 C$ \\
\hline Butyric acid productivity (g/L/d) & $1.68 \pm 0.19 A$ & $1.90 \pm 0.27 A$ & $2.69 \pm 0 B$ \\
\hline Carboxylic acids productivity (g/L/d) & $2.83 \pm 0.3 A$ & $3.08 \pm 0.38 A$ & $4.64 \pm 0.03 B$ \\
\hline $\mathrm{H}_{2}$ productivity $(L / L / d)$ & $0.26 \pm 0.03 A$ & $0.31 \pm 0.04 A B$ & $0.35 \pm 0.01 B$ \\
\hline
\end{tabular}

a Solids residence time = Total working volume of fermentor/Flow rate of liquid out of fermentor.

${ }^{b}$ Percent of butyric acid from the total carboxylic acids.

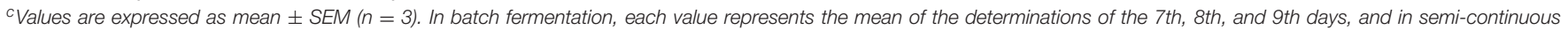
fermentation, the last three days. Values in the same row followed by the same capital letter are not significantly different at $P=0.05$, according to Duncan's multiple range test.

of acetic acid can be obtained from $1 \mathrm{~g}$ of hemicellulose (defined as xylan). Based on Equations $(1,4), 0.54 \mathrm{~g}$ of butyric acid can be obtained from $1 \mathrm{~g}$ of cellulose; based on Equations $(2,6), 0.56 \mathrm{~g}$ of butyric acid can be obtained from $1 \mathrm{~g}$ of hemicellulose. According to the calculation results above, $0.60 \mathrm{~g}$ of acetic acid or $0.43 \mathrm{~g}$ of butyric acid, theoretically, can be produced from the $\mathrm{NaOH}$ pretreated rice straw used in this study as it contained $53.0 \%$ cellulose and $27.4 \%$ hemicellulose. 


\section{Actual Yield of Butyric Acid Production From Rice Straw by Undefined Mixed Culture}

Based on the fermentation results from the batch and semicontinuous operations, the ratios of actual yield to theoretical yield of butyric acid production were calculated (Table 2). In the three runs of butyric acid fermentation, the amounts of pretreated rice straw fed in the reactor were 1839, 1814, and $6779 \mathrm{~g}$ and the actual yields of butyric acid were 294, 317 , and $1189 \mathrm{~g}$, respectively, corresponding to 37 to $41 \%$ of the maximum theoretical yield based on the amount of rice straw fed into the reactor. Because the mixed culture produced carboxylic acids with different carbon chain lengths, the acetic acid equivalent (Aceq) was introduced to represent the amount of acetic acid that could have been produced if all the produced carboxylic acids were acetic acid (Fu and Holtzapple, 2011). The acetic acid equivalent $\alpha$ can be calculated from Equation (7).

$$
\begin{aligned}
\text { Aceq } \alpha(\mathrm{mol} / \mathrm{L})= & \text { Acetic acid }(\mathrm{mol} / \mathrm{L}) \\
& + \text { Propionic acid }(\mathrm{mol} / \mathrm{L}) \times 1.75 \\
& + \text { Butyric acid }(\mathrm{mol} / \mathrm{L}) \times 2.5 \\
& + \text { Valeric acid }(\mathrm{mol} / \mathrm{L}) \times 3.25 \\
& + \text { Caproic acid }(\mathrm{mol} / \mathrm{L}) \times 4.0
\end{aligned}
$$

On a mass basis, the acetic acid equivalent can be expressed as Equation (8).

$$
\operatorname{Aceq}(\mathrm{g} / \mathrm{L})=\operatorname{Aceq} \alpha(\mathrm{mol} / \mathrm{L}) \times 60
$$

The measured carboxylic acids (including acetic, propionic, $i$ butyric, $n$-butyric, $i$-valyric, $n$-valyric, $i$-caproic and $n$-caproic acids) presented in Table 1 were converted to Aceq according to Equations $(7,8)$. Using this conversion, approximately 69 to $74 \%$ of the maximum theoretical yield of acetic acid was obtained. It is necessary to emphasize that the fermentation of monosaccharides by open mixed cultures may be expected to be completely converted to acetic acid with a carbon efficiency of
$100 \%$ as presented in Equations $(9,10)$ (Holtzapple and Granda, 2009; Fu and Holtzapple, 2011).

$$
\begin{aligned}
\mathrm{C}_{6} \mathrm{H}_{12} \mathrm{O}_{6} & \rightarrow 3 \mathrm{CH}_{3} \mathrm{COOH} \\
2 \mathrm{C}_{5} \mathrm{H}_{10} \mathrm{O}_{5} & \rightarrow 5 \mathrm{CH}_{3} \mathrm{COOH}
\end{aligned}
$$

If the above viewpoint holds, the ratios of actual yields to theoretical yields obtained in this study would be much lower than those of calculated using Equations $(9,10)$ instead of Equations $(3,5)$.

\section{Comparative Assessment of Butyric Acid Production by Undefined Mixed Culture and Pure Culture}

Despite its potential as a substitute for petroleum-derived butyric acid, the commercial production and application of biomassderived butyric acid has been hindered by the high cost of microbial fermentation. To overcome this limitation, butyric acid fermentation has been extensively studied using various producers in combination with several substrates in batch, semicontinuous, continuous and cell-recycled modes (see Table 3 ). The presently preferred producers for butyric acid fermentation are the species of Clostridium, including C. butyricum, $C$. tyrobutyricum, C. thermobutyricum, C. acetobutylicum, and $C$. populeti (Zhang et al., 2009). C. tyrobutyricum is regarded as the most promising microorganism for industrial applications owing to its high productivity and selectivity (Dwidar et al., 2013). By improving the fermentation method, for example, immobilizing microbial cells to increase the biomass in the reactor and prevent the loss of cells greatly enhanced both the productivity and selectivity (Jiang et al., 2010); using the semi-continuous mode instead of the batch mode led to a higher final product concentration (Wei et al., 2013).

Starchy substrate (such as corn) and simple sugars (such as molasses and glucose) are the traditional carbon sources for butyric acid fermentation. With the increasing price of the traditional feedstocks, attention turns to low-cost lignocellulosic biomass, which is considered a promising carbon source for industrial production of butyric acid. However, the pure culture of butyric acid-producing strains cannot utilize cellulose. C.

TABLE 2 | The ratios of actual yield to theoretical yield of butyric acid fermentation in a stirred-tank reactor.

\begin{tabular}{lccc}
\hline & Batch fermentation 1 & Batch fermentation 2 & Semi-continuous fermentation \\
\hline Cumulative rice straw fed (g) & 1839 & 1814 & 6779 \\
Theoretical yield of butyric acid (g) & 790.8 & 780 & 2915 \\
Actual yield of butyric acid (g) & 293.6 & 316.9 & 1189.4 \\
Actual yield of butyric acid/Theoretical yield (\%) & 37 & 41 & 41 \\
Theoretical yield of total carboxylic acids (g) & 1103.4 & 508.6 & 4067.4 \\
Actual yield of total carboxylic acids (g) & 513.2 & 774.3 & 2047.7 \\
Acetic acid equivalent (g) & 764.7 & 71 & 3025.2 \\
Actual yield of carboxylic acids/Theoretical yield (\%) & 69 & & 74 \\
\hline
\end{tabular}

${ }^{a}$ The actual yield of carboxylic acids is represented by acetic acid equivalent. 
TABLE 3 | Summary of the results of butyric acid fermentation using undefined mixed culture and pure culture.

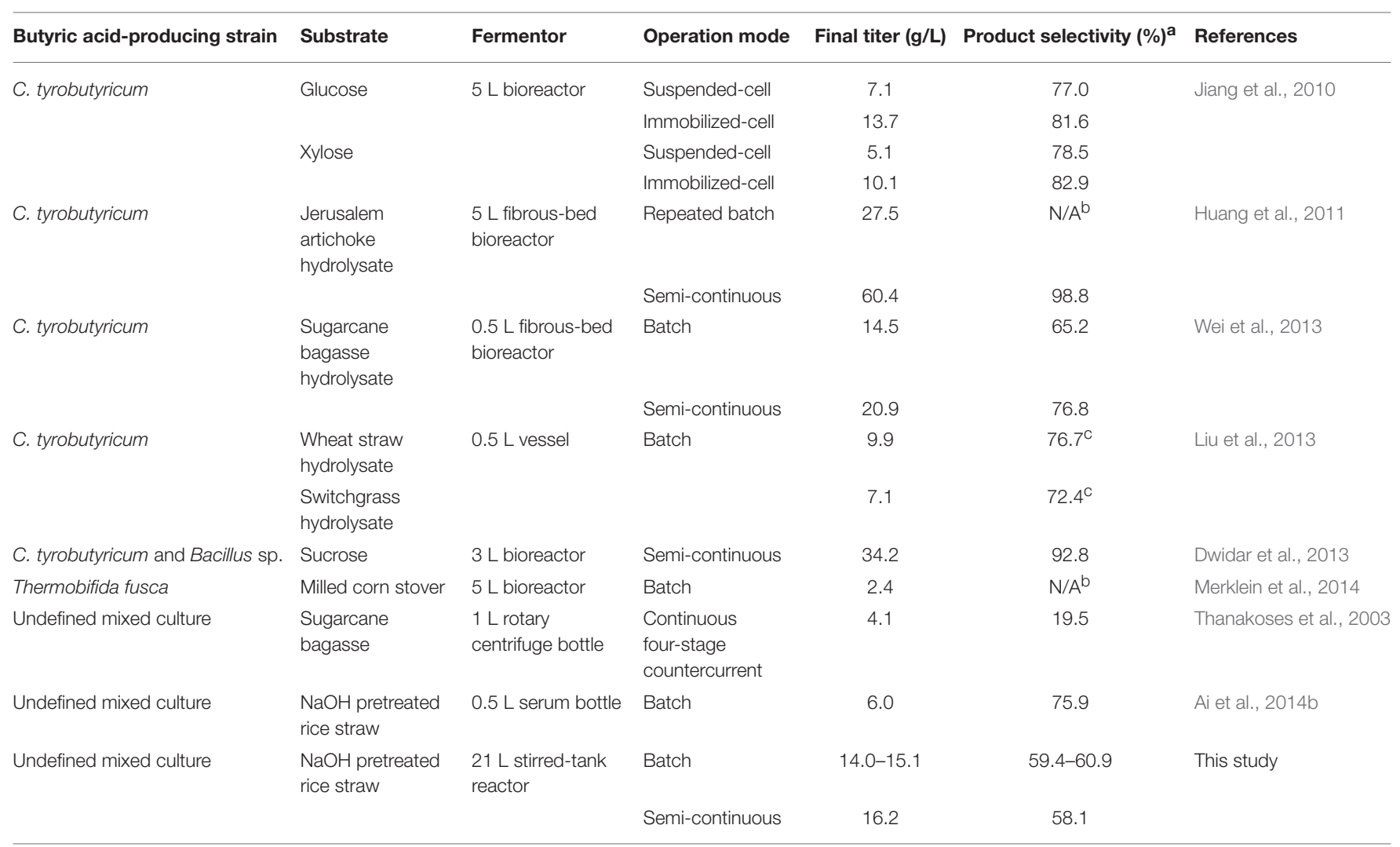

${ }^{a}$ Percent of butyric acid from the total carboxylic acids.

${ }^{b} N / A$, not available.

${ }^{c}$ The value was not available from the original reference, but was calculated from the data estimated from the figures.

tyrobutyricum can only utilize monosaccharides like glucose, xylose and fructose, even not disaccharides, such as sucrose and lactose. By co-culturing with a Bacillus sp. capable of producing a levansucrase enzyme, C. tyrobutyricum ATCC 25755 is able to ferment sucrose to butyric acid (Dwidar et al., 2013). To use lignocellulose as a carbon source, cellulolytic enzymes are required to break down substrate into single sugars that are further utilized by butyric acid-producing strain. It was reported that $C$. thermobutyricum was co-cultured with C. thermocellum for butyric acid production from cellulosic substrate (Dwidar et al., 2012). In the co-culture system, C. thermocellum produces cellulase and hemicellulase that hydrolyzes cellulose and hemicellulose into pentose and hexose sugars. Because of its higher growth rate and the quicker fermentation rate of pentose and hexose, C. thermobutyricum utilizes the monosaccharides liberated by $C$. thermocellum to produce butyric acid. A cellulolytic bacterium, Thermobifida fusca, was also reported to ferment a cellulosic substrate to butyric acid, in which $2.37 \mathrm{~g} / \mathrm{L}$ of butyric acid was produced from milled corn stover (Merklein et al., 2014).

Using pure culture and defined mixed culture, the degradation efficiency of lignocellulosic feedstocks and butyric acid production are limited. By using undefined mixed culture, degradation efficiency is enhanced and supplementary cellulolytic enzymes are not necessary. A patented undefined mixed culture-based process, MixAlco ${ }^{\mathrm{TM}}$, has been developed to convert organic biomass to carboxylate acids (mainly acetic acid) which are then further converted to mixed alcoholic fuels (Granda et al., 2009; Holtzapple and Granda, 2009). The results from using the MixAlco ${ }^{\mathrm{TM}}$ process have demonstrated that undefined mixed culture is efficient at converting lignocellulosic biomass to carboxylic acids. A very few studies have been undertaken to investigate the production of butyric acid as the desired product using undefined mixed culture from lignocellulosic feedstocks, but suffering from low final product concentration and low selectivity.

A mixed culture produces mixed products. It has been revealed that the cellulose-degrading butyrate-producing mixed culture used in this study is composed of cellulolytic and xylanolytic bacteria, butyrate-producing bacteria and other acidogenic bacteria, including Bacteroides cellulosilyticus, Clostridium cellulolyticum, Bacteroides graminisolvens, Bacteroides xylanisolvens, Cellulosilyticum ruminicola, Eubacterium xylanophilum, Clostridium polysaccharolyticum, Clostridium saccharolyticum, Thermincola carboxydiphila, Clostridium xylanolyticum, Clostridium algidixylanolyticum, Xylanibacter oryzae (Ai et al., 2013). n-Butyric and acetic acids were the main liquid products, and another six carboxylic acids, including propionic, $i$-butyric, $i$-valeric, $n$-valeric, $i$-caproic and $n$-caproic, were detected in the fermentation broth. Therefore, 
high selectivity for the desired product is especially crucial for mixed culture-based processes.

The butyric acid production in the presence of an undefined mixed culture system is completed with the collaboration of cellulose- and hemicellulose-degrading bacteria, butyric acidproducing bacteria, acetic acid-producing bacteria and other bacteria. The cellulose- and hemicellulose-degrading bacteria provide substrate for acidogenic bacteria, and in return the acidogenic bacteria relieve substrate inhibition for celluloseand hemicellulose-degrading bacteria. However, the bacteria groups with different functions require different growth and production conditions. As environmental factors change, the balance based on mutually beneficial relationships will likely be broken. The bacterial community structure shifts and hence the product spectrum varies. It was found that fermentation mode (batch or repeated-batch operation) greatly influences butyric acid production. The shift of microbial community structure is believed to be the reason behind the selectivity changes. When butyric acid production underwent a decrease, it was observed an increase in population of acetate- and valerate-producing bacteria and a decrease in butyrate-producing bacteria (Ai et al., 2014b). Thus, stability of microbial community structure is required for butyric acid production with undefined mixed culture.

Besides the growth and decline of population of byproduct-producing bacteria, the shift in metabolic pathway of butyrate-producing bacteria causes changes in selectivity of butyric acid production. In acidogenic fermentation systems, the microbes tend to produce acetic acid rather than butyric acid to meet their energy demands because more ATP is synthesized from the acetate metabolic pathway (Equation 3) than the butyrate metabolic pathway (Equation 4). In order for microorganisms to respond to adverse situations like $\mathrm{pH}$ decreases and excess $\mathrm{NADH}$ and $\mathrm{H}^{+}$, excreted acetic acid will be taken up and converted into butyric acid. Metabolism will then shift to butyric acid formation, which explains why the optimal $\mathrm{pH}$ for butyric acid fermentation is in the acidic $\mathrm{pH}$ range and why acetic acid formation peaked and then declined in the first 3 days (Ai et al., 2014a). As discussed above, low-pH

\section{REFERENCES}

Agler, M. T., Wrenn, B. A., Zinder, S. H., and Angenent, L. T. (2011). Waste to bioproduct conversion with undefined mixed cultures: the carboxylate platform. Trends Biotechnol. 29, 70-78. doi: 10.1016/j.tibtech.2010.11.006

Ai, B., Li, J., Chi, X., Meng, J., Jha, A., Liu, C., et al. (2014a). Effect of pH and buffer on butyric acid production and microbial community characteristics in bioconversion of rice straw with undefined mixed culture. Biotechnol. Bioprocess Eng. 19, 676-686. doi: 10.1007/s12257-013-0655-Z

Ai, B., Li, J., Chi, X., Meng, J., Liu, C., and Shi, E. (2014b). Butyric acid fermentation of sodium hydroxide pretreated rice straw with undefined mixed culture. J. Microbiol. Biotechnol. 24, 629-638. doi: 10.4014/jmb.1309.09078

Ai, B., Li, J., Song, J., Chi, X., Meng, J., Zhang, L., et al. (2013). Butyric acid fermentation from rice straw with undefined mixed culture: enrichment and selection of cellulolytic butyrate-producing microbial community. Int. J. Agric. Biol. 15, 1075-1082.

Albuquerque, M. G. E., Martino, V., Pollet, E., Avérous, L., and Reis, M. A. M. (2011). Mixed culture polyhydroxyalkanoate (PHA) production from volatile stress induces microbes to produce butyric acid not acetic acid for less acidic end groups $(-\mathrm{COOH})$. But neutral $\mathrm{pH}$ reduces the harm to microbial cell caused by undissociated carboxylic acids, and hence improves the substrate utilization and total carboxylic acids production. So, butyric acid production is optimal at neutral to slightly acidic $\mathrm{pH}$ range that maintains constant stress for butyric acid formation, but does not inhibit the microbial metabolism.

\section{CONCLUSIONS}

A stirred-tank reactor was developed for butyric acid production from $\mathrm{NaOH}$ pretreated rice straw with a cellulolytic butyrate-producing microbial community. Of the two fermentation operations tested in this study, semi-continuous fermentation achieved the higher butyric acid productivity of $2.69 \mathrm{~g} /(\mathrm{L} \cdot \mathrm{d})$ with a concentration of $16.2 \mathrm{~g} / \mathrm{L}$. The actual yield of butyric acid corresponded to $41 \%$ of the maximum theoretical yield based on the amount of rice straw fed into the reactor. This study successfully demonstrated a CBP process for the bioconversion of low grade lignocellulosic biomass into butyric acid without supplementary cellulolytic enzymes.

\section{AUTHOR CONTRIBUTIONS}

BA designed the experiment, operated the reactor and drafted the manuscript. XC and JM did the measurements and participated in data analysis. ZS, LZ, and XZ contributed in writing the draft. JL led and coordinated the overall project. All authors read and approved the final manuscript.

\section{FUNDING}

This work was financially supported by the National Natural Science Foundation of China (Grant No. 51478141), Natural Science Foundation of Hainan Province of China (Grant No. 20154194) and State Key Laboratory of Urban Water Resource and Environment, Harbin Institute of Technology (Grant No. 2013DX11). fatty acid (VFA)-rich streams: effect of substrate composition and feeding regime on PHA productivity, composition and properties. J. Biotechnol. 151, 66-76. doi: 10.1016/j.jbiotec.2010.10.070

Chan, W. N., Fu, Z., and Holtzapple, M. T. (2011). Co-digestion of swine manure and corn stover for bioenergy production in MixAlco ${ }^{\text {TM }}$ consolidated bioprocessing. Biomass Bioenergy 35, 4134-4144. doi: 10.1016/j.biombioe.2011.06.053

Cheng, C.-L., Lo, Y.-C., Lee, K.-S., Lee, D.-J., Lin, C.-Y., and Chang, J.-S. (2011). Biohydrogen production from lignocellulosic feedstock. Bioresour. Technol. 102, 8514-8523. doi: 10.1016/j.biortech.2011.04.059

Dwidar, M., Kim, S., Jeon, B. S., Um, Y., Mitchell, R. J., and Sang, B.-I. (2013). Co-culturing a novel Bacillus strain with Clostridium tyrobutyricum ATCC 25755 to produce butyric acid from sucrose. Biotechnol. Biofuels 6:35. doi: 10.1186/1754-6834-6-35

Dwidar, M., Park, J.-Y., Mitchell, R. J., and Sang, B.-I. (2012). The future of butyric acid in industry. Sci. World J. 2012, 1-9. doi: 10.1100/2012/471417

Forrest, A. K., Sierra, R., and Holtzapple, M. T. (2010). Suitability of pineapple, Aloe vera, molasses, glycerol, and office paper as substrates 
in the MixAlco process ${ }^{\mathrm{TM}}$. Biomass Bioenergy 34, 1195-1200. doi: 10.1016/j.biombioe.2010.03.013

Fu, Z., and Holtzapple, M. T. (2010). Consolidated bioprocessing of sugarcane bagasse and chicken manure to ammonium carboxylates by a mixed culture of marine microorganisms. Bioresour. Technol. 101, 2825-2836. doi: 10.1016/j.biortech.2009.11.104

Fu, Z., and Holtzapple, M. T. (2011). Anaerobic thermophilic fermentation for carboxylic acid production from in-storage air-lime-treated sugarcane bagasse. Appl. Microbiol. Biotechnol. 90, 1669-1679. doi: 10.1007/s00253-011-3178-6

Granda, C. B., Holtzapple, M. T., Luce, G., Searcy, K., and Mamrosh, D. L. (2009). Carboxylate platform: the MixAlco process Part 2: process economics. Appl. Biochem. Biotechnol. 156, 107-124. doi: 10.1007/s12010-008-8481-Z

Hao, X., Zhou, M., Yu, H., Shen, Q., and Lei, L. (2006). Effect of sodium ion concentration on hydrogen production from sucrose by anaerobic hydrogen-producing granular sludge. Chin. J. Chem. Eng. 14, 511-517. doi: 10.1016/S1004-9541(06)60106-7

Holtzapple, M. T., and Granda, C. B. (2009). Carboxylate platform: the MixAlco process Part 1: comparison of three biomass conversion platforms. Appl. Biochem. Biotechnol. 156, 95-106. doi: 10.1007/s12010-008-8466-y

Huang, J., Cai, J., Wang, J., Zhu, X., Huang, L., Yang, S.-T., et al. (2011). Efficient production of butyric acid from Jerusalem artichoke by immobilized Clostridium tyrobutyricum in a fibrous-bed bioreactor. Bioresour. Technol. 102, 3923-3926. doi: 10.1016/j.biortech.2010.11.112

Jiang, L., Wang, J., Liang, S., Wang, X., Cen, P., and Xu, Z. (2010). Production of butyric acid from glucose and xylose with immobilized cells of Clostridium tyrobutyricum in a fibrous-bed bioreactor. Appl. Biochem. Biotechnol. 160, 350-359. doi: 10.1007/s12010-008-8305-1

Lee, J. M., Upare, P. P., Chang, J. S., Hwang, Y. K., Lee, J. H., Hwang, D. W., et al. (2014). Direct hydrogenation of biomass-derived butyric acid to n-butanol over a ruthenium-tin bimetallic catalyst. ChemSusChem 7, 2998-3001. doi: $10.1002 /$ cssc. 201402311

Liu, S., Bischoff, K. M., Leathers, T. D., Qureshi, N., Rich, J. O., and Hughes, S. R. (2013). Butyric acid from anaerobic fermentation of lignocellulosic biomass hydrolysates by Clostridium tyrobutyricum strain RPT-4213. Bioresour. Technol. 143, 322-329. doi: 10.1016/j.biortech.2013.06.015

Merklein, K., Fong, S. S., and Deng, Y. (2014). Production of butyric acid by a cellulolytic actinobacterium Thermobifida fusca on cellulose. Biochem. Eng. J. 90, 239-244. doi: 10.1016/j.bej.2014.06.012
Olson, D. G., McBride, J. E., Shaw, A. J., and Lynd, L. R. (2012). Recent progress in consolidated bioprocessing. Curr. Opin. Biotechnol. 23, 396-405. doi: 10.1016/j.copbio.2011.11.026

Richter, H., Qureshi, N., Heger, S., Dien, B., Cotta, M. A., and Angenent, L. T. (2012). Prolonged conversion of n-butyrate to n-butanol with Clostridium saccharoperbutylacetonicum in a two-stage continuous culture with in-situ product removal. Biotechnol. Bioeng. 109, 913-921. doi: 10.1002/bit. 24380

Temudo, M. F., Mato, T., Kleerebezem, R., and van Loosdrecht, M. C. M. (2009). Xylose anaerobic conversion by open-mixed cultures. Appl. Microbiol. Biotechnol. 82, 231-239. doi: 10.1007/s00253-008-1749-y

Thanakoses, P., Mostafa, N., and Holtzapple, M. (2003). Conversion of sugarcane bagasse to carboxylic acids using a mixed culture of mesophilic microorganisms. Appl. Biochem. Biotechnol. 107, 523-546. doi: 10.1385/ABAB:107:1-3:523

Van Soest, P. J., Robertson, J. B., and Lewis, B. A. (1991). Methods for dietary fiber, neutral detergent fiber, and nonstarch polysaccharides in relation to animal nutrition. J. Dairy Sci. 74, 3583-3597. doi: 10.3168/jds.S0022-0302(91) 78551-2

Wei, D., Liu, X., and Yang, S.-T. (2013). Butyric acid production from sugarcane bagasse hydrolysate by Clostridium tyrobutyricum immobilized in a fibrous-bed bioreactor. Bioresour. Technol. 129, 553-560. doi: 10.1016/j.biortech.2012.11.065

Zhang, C., Yang, H., Yang, F., and Ma, Y. (2009). Current progress on butyric acid production by fermentation. Curr. Microbiol. 59, 656-663. doi: 10.1007/s00284009-9491-y

Conflict of Interest Statement: The authors declare that the research was conducted in the absence of any commercial or financial relationships that could be construed as a potential conflict of interest.

Copyright (c) 2016 Ai, Chi, Meng, Sheng, Zheng, Zheng and Li. This is an openaccess article distributed under the terms of the Creative Commons Attribution License (CC BY). The use, distribution or reproduction in other forums is permitted, provided the original author(s) or licensor are credited and that the original publication in this journal is cited, in accordance with accepted academic practice. No use, distribution or reproduction is permitted which does not comply with these terms. 